\title{
Effect of Nitrogen Plasma Afterglow on Amorphous Carbon Nitride Thin Films Deposited by Laser Ablation
}

\author{
A. Alkhawwam ${ }^{a, *}$, B. Abdallah ${ }^{a}, \mathrm{~K} \mathrm{Kayed}^{b}$ And K. Alshoufi $^{b}$ \\ ${ }^{a}$ Physics Department, Atomic Energy Commission, Damascus, Syria \\ ${ }^{b}$ Physics Department, Faculty of Science, Damascus University, Syria
}

(Received February 9, 2011; in final form April 19, 2011)

\begin{abstract}
By employing pulsed laser deposition, amorphous carbon nitride $\left(\mathrm{a}-\mathrm{CN}_{x}\right)$ thin films, were prepared on unheated Si (100). Investigation of compositional and structural modifications induced by microwave nitrogen plasma afterglow on amorphous carbon nitride thin films, has been carried out in the range of nitrogen pressure 10-1000 Pa. The role of nitrogen plasma afterglow on the physicochemical and structural characteristics of a- $\mathrm{CN}_{x}$ was explored using the diagnostic techniques: Raman spectroscopy, X-ray photoelectron spectroscopy, scanning electron microscopy and atomic force microscopy. Upon analyzing the Raman and X-ray photoelectron spectra, it is concluded that employing nitrogen plasma afterglow during the films deposition favors, in general, the increase in nitrogen content and the formation of $s p^{2}$ bonding in the a- $\mathrm{CN}_{x}$ films. The analysis of scanning electron and atomic force microscopy images demonstrated that the films had a granular structure formed from particles coalesced together into cauliflower-like clusters and the particles size increased by increasing nitrogen pressure. A 2D atomic force microscopy line profile measurements provide evidence to a decrease in size of clusters using nitrogen plasma afterglow which could be due to the annihilation of excess vacancies and/or the elimination of grain boundaries. These analyses were found to be quite reliable to help understand the effects of microwave nitrogen plasma afterglow on amorphous carbon nitride thin films.
\end{abstract}

PACS: 82.33.Xj, 81.15.Fg, 78.30.Jw, 68.49.Uv, 68.37.Ps, 68.37.Hk

\section{Introduction}

Carbon nitride films have been intensively investigated during the last two decades, since Cohen and Liu predicted the hypothetical superhard $\beta-\mathrm{C}_{3} \mathrm{~N}_{4}$ crystalline phase $[1,2]$. Although many authors have attempted the experimental synthesis of these crystalline carbon nitride films, there has been no clear evidence on the formation of the crystalline stoichiometric phase $\beta-\mathrm{C}_{3} \mathrm{~N}_{4}[3,4]$ and serious problems have emerged during this production through a wide range of deposition techniques and conditions. The films obtained are mostly amorphous or partly crystalline [5-7]. However, amorphous carbon nitride a- $\mathrm{CN}_{x}$ films also exhibit significant properties and potential applications, such as high hardness and elasticity $[8,9]$, low friction coefficient $[10,11]$, significant optical properties $[12,13]$, and for its biocompatibility features [14-16].

One of the applications for a- $\mathrm{CN}_{x}$ films is the wear protective coatings, e.g. the protective overcoat layer for magnetic thin-film rigid disks $[17,18]$. These interesting properties seem to be attributed to the bonding state of a- $\mathrm{CN}_{x}$ films and their specific microstructure, which depends strongly on the deposition conditions, and may contain different configurations of bonds

* corresponding author; e-mail: scientific@aec.org.sy $\left(s p^{1}, s p^{2}\right.$ and $\left.s p^{3}\right)$ [19-22]. Therefore, studying the structural characteristics of these films is highly important to understand their physical properties.

Various techniques were used to deposit amorphous carbon nitride films such as plasma enhanced chemical vapor deposition (PECVD) [23-25], reactive sputtering [26-28], and pulsed laser deposition (PLD). PLD is a renowned laboratory tool capable of growing films of a wide range of materials including $\mathrm{CN}_{x}$ films which have been investigated over many years [29-33].

In order to increase nitrogen dissociation and produce atomic and ionized nitrogen and then incorporate it in the $\mathrm{CN}_{x}$ films, several techniques were tried, including additional ways for plasma assisted nitrogen activation [34-37].

In this study we discuss the effect of nitrogen plasma afterglow (NPA) on amorphous carbon nitride thin films deposited by laser ablation. A comparative investigation of compositional and structural modifications of the a- $\mathrm{CN}_{x}$ films induced by NPA is explored using different diagnostic techniques.

\section{Experimental}

Amorphous carbon nitride a- $\mathrm{CN}_{x}$ films were deposited onto non-heated polished $n$-type Si (100). The $Q$ -switched Nd:YAG pulsed laser (RD-YG-300) was operated at $1 \mathrm{~Hz}$ repetition rate and of emission at the funda- 
mental line $(\lambda=1064 \mathrm{~nm})$ with a 20 ns pulse duration. The laser beam was focused on the graphite target at an incidence angle of $45^{\circ}$ and a laser fluence of $12.8 \mathrm{~J} \mathrm{~cm}^{-2}$. The substrates were installed on an aluminum holder at a distance of about $2 \mathrm{~cm}$ from the target. Two series of carbon nitride films were prepared in two different atmospheres. One (series I) is a deposition in an atmosphere of pure nitrogen molecular gas (purity 99.999\%). The other (series II) is a deposition in a NPA generated by Microwave SAIREM GMP 20 KEDS at fixed transmitted power of $1000 \mathrm{~W}$. The deposition was performed in $\mathrm{N}_{2}$ or NPA pressures changing from 10 to 100 , to 300 , to 500 , and to $1000 \mathrm{~Pa}$. The schematic and a photo of the experimental setup are shown in Fig. 1. More details about the technique and deposition procedures are explained in previous works $[22,29]$.

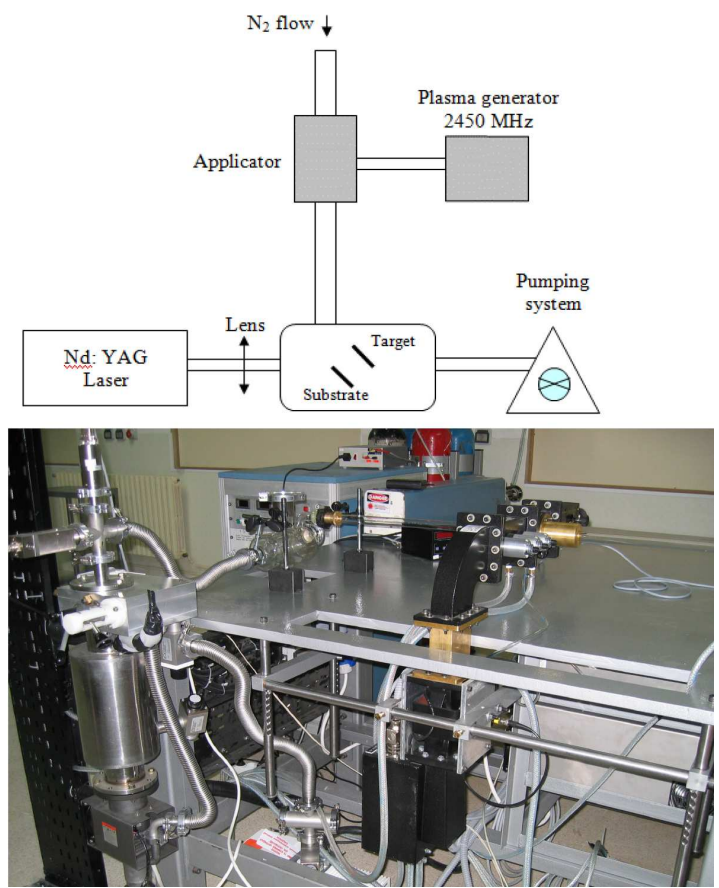

Fig. 1. Schematic and photo of the experimental setup.

To investigate the structure and composition of the films, different techniques are used.

Micro-Raman backscattering spectra of the films were recorded on a Jobin-Yvon T64000 operating with a $514.5 \mathrm{~nm}$ line of argon laser as the excitation source and a resolution of $2 \mathrm{~cm}^{-1}$. Care was taken to avoid damage due to laser heating during the measurements. The Raman spectra were fitted by the typical Gaussian-Lorentzian components with no asymmetry.

The chemical components of the films studied in this paper were determined using a LEYBOLD LHS11 MCP $\mathrm{X}$-ray photoelectron spectroscopy (XPS). Survey and multiregion spectra were recorded at $\mathrm{C} 1 s, \mathrm{~N} 1 s$ and $\mathrm{O} 1 s$ photoelectron peaks. Each spectra region was scanned at least 10 times in order to get well detected signal-to-noise ratios. The X-ray gun $\left(\mathrm{Mg} K_{\alpha}\right.$ photon energy $\left.1253.6 \mathrm{eV}\right)$ was operated at $120 \mathrm{~W}, 12 \mathrm{kV}$ with a current emission of $10 \mathrm{~mA}$ as an excitation source under high vacuum conditions of $\approx 10^{-8} \mathrm{~Pa}$.

The chemical composition of the deposited films can be obtained according to nitrogen to carbon $(N / C)$ and the oxygen to carbon atomic ratio $(O / C)$. The $N / C$ and $O / C$ content in the films were evaluated using $N / C=(A N / 1.68) /(A C / 1.00)$ and $O / C=$ $(A O / 2.49) /(A C / 1.00)$, where $A N, A O$ and $A C$ are the areas under the $\mathrm{N} 1 s, \mathrm{O} 1 s$ and $\mathrm{C} 1 s$ core level spectra and the constants of $1.68,2.49$ and 1.00 are the atomic sensitivity factors of $\mathrm{N}, \mathrm{O}$, and $\mathrm{C}$, respectively [38].

The surface morphology and film thickness were characterized by scanning electron microscopy (SEM) using a JEOL-type JSM 6400F, at 7000, 30000 and 100000× magnification. The electron beam was operated at low voltage in order to avoid charge effects on the films.

The surface topography of the films was characterized by Auto Probe CP-PSI atomic force microscopy (AFM) from Park Scientific Instruments with high lateral and vertical resolutions and three different scan sizes: $13 \times 13$, $5 \times 5$ and $1 \times 1 \mu \mathrm{m}^{2}$.

In order to verify if the prepared a- $\mathrm{CN}_{x}$ thin films are amorphous or crystalline, $1^{\circ}$ grazing angle $\mathrm{X}$-ray diffraction (XRD) measurements were carried out using Stoe transmission diffractometer (STADIP) with reflection samples holder (starting from $\omega=90^{\circ}$ ) for all prepared carbon nitride thin films.

\section{Results and discussion}

\subsection{Raman spectroscopy measurements}

The Raman spectra are extensively used to probe the quality of carbon based films, because from the Raman spectra, one can distinguish different bonding types and domain sizes of carbon based films.

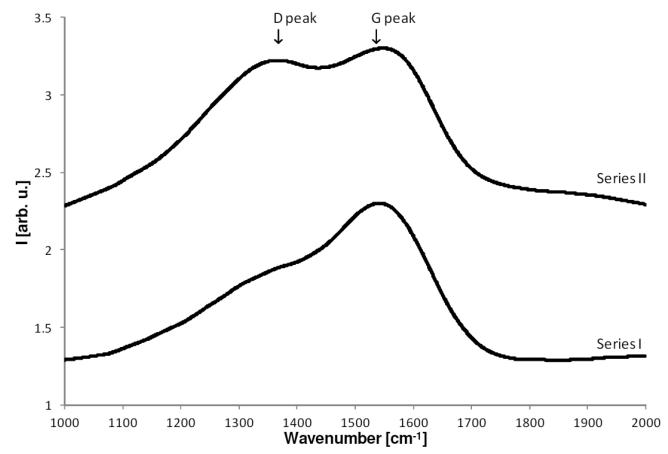

Fig. 2. Raman spectra of a- $\mathrm{CN}_{x}$ films show the $D$ and $G$ peaks in series I and series II at $1000 \mathrm{~Pa}$.

As presented in Fig. 2, the Raman spectra of carbon nitride films in the wave number region of $1000-2000 \mathrm{~cm}^{-1}$ exhibit usually two main peaks positioned at $\approx 1350$ and 


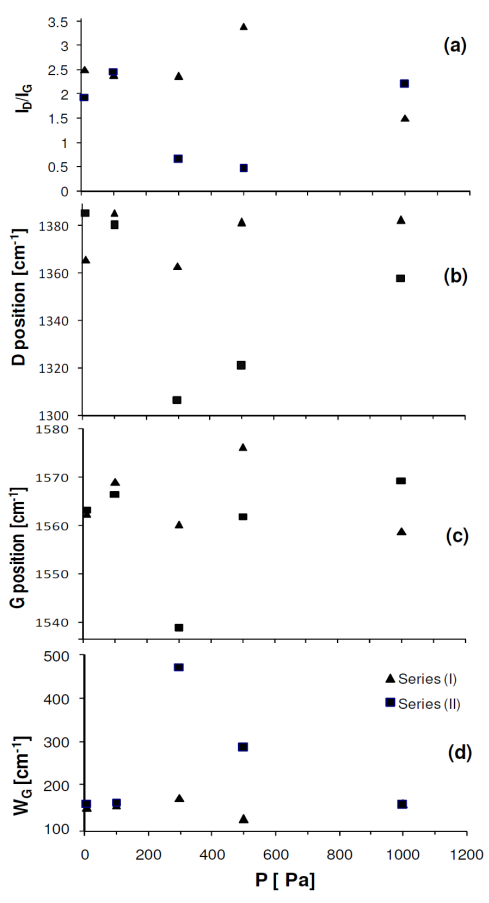

Fig. 3. Variation of (a) $I_{D} / I_{G}$, (b) $D$ peak position, (c) $G$ peak position and (d) $G$ width of the Raman spectra of a-CN $\mathrm{CN}_{x}$ in series I and series II films with nitrogen pressure.

$\approx 1540-1580 \mathrm{~cm}^{-1}$, denoted by $D$ and $G$ peaks, respectively. All Raman spectra were fitted into two Gaussian-Lorentzian peaks so as to identify their position and relative intensities. The $G$-peak originates from the lattice vibrations in the plane of the graphite-like rings (zone center phonon dispersion in the graphite crystal). The low-frequency $D$-peak is associated with structural disorder in the graphite-like phase of carbon nitride films. Many reports have shown that the $G$-peak position, $D$ -peak position, $G$-peak width and the $I_{D} / I_{G}$ intensity ratio are good structural parameters for carbon nitride films [39-41].

In general, different curves exist to fit these types of spectra, in our study the ratio of the intensity of disorder peak to graphite peak $\left(I_{D} / I_{G}\right)$ is calculated from the area of Gaussian-Lorentzian peaks.

Figure 3 shows the influences of NPA and nitrogen pressure on $G$-peak width $\left(W_{G}\right), G$-peak position, $D$ -peak position and the $I_{D} / I_{G}$ intensity ratio. Quite different from the literature report, which indicated the increase of the ratio of $I_{D} / I_{G}$ with nitrogen ion energy [42], our results show that for the films prepared at nitrogen pressure lower than $1000 \mathrm{~Pa}$, the $I_{D} / I_{G}$ for all spectra of series II is always lower than that of series I. On the contrary, for the films prepared at nitrogen pressure of $1000 \mathrm{~Pa}$, one can notice the opposite result, i.e. the $I_{D} / I_{G}$ of series II is higher than that of series I. Furthermore, an increase of the $G$ peak width and a shift of the Raman peaks towards lower frequencies are observed for most of the spectra of series II. These low values of $I_{D} / I_{G}$ ratio in the Raman spectra of series II could indicate the limited clustering of the $s p^{2}$ sites in rings.

Consequently, the shift of the Raman peaks towards lower frequencies and the decrease in the $I_{D} / I_{G}$ intensity ratio can be explained by either some increase in the $s p^{3}$ bonding fraction, or the decrease in the size of the graphitic clusters [41-44]. The latter case is the one which is believed to be more likely to take place.

\section{TABLE}

XPS elemental composition analyses for a- $\mathrm{CN}_{x}$ films obtained in series I and II.

\begin{tabular}{c|c|c|c|c|c|c}
\hline \hline $\mathrm{O} / \mathrm{C}$ & $\mathrm{N} / \mathrm{C}$ & $\mathrm{O} \%$ & $\mathrm{~N} \%$ & $\mathrm{C} \%$ & & $\begin{array}{c}\text { Pressure } \\
{[\mathrm{Pa}]}\end{array}$ \\
\hline 0.161 & 0.294 & 11.1 & 20.2 & 68.7 & Series I & 10 \\
0.221 & 0.327 & 14.3 & 21.1 & 64.6 & & 100 \\
0.182 & 0.275 & 12.5 & 18.9 & 68.6 & & 300 \\
0.163 & 0.088 & 13.0 & 7.1 & 79.9 & & 500 \\
0.173 & 0.107 & 13.5 & 8.4 & 78.1 & & 1000 \\
\hline 0.159 & 0.302 & 11.0 & 20.6 & 68.4 & Series II & 10 \\
0.174 & 0.218 & 12.5 & 15.6 & 71.8 & & 100 \\
0.259 & 0.355 & 16.1 & 22.0 & 61.9 & & 300 \\
0.367 & 0.566 & 19.0 & 29.3 & 51.7 & & 500 \\
0.271 & 0.498 & 15.3 & 28.1 & 56.5 & & 1000
\end{tabular}

In addition, as shown in Fig. 3 and Table, the high increase of the $I_{D} / I_{G}$ intensity for the films prepared in NPA at nitrogen pressure of $1000 \mathrm{~Pa}$ (series II) compared with the $I_{D} / I_{G}$ intensity for the films prepared in 
nitrogen pressure of $1000 \mathrm{~Pa}$ (series I), could indicate an increase in network disorder $[29,44]$.

\subsection{X-ray photoelectron spectroscopy}

Although XPS analysis is used extensively to study carbon nitride films for the characterization of bond types and the chemical local environment around $\mathrm{C}, \mathrm{N}$ and $\mathrm{O}$ of $\mathrm{CN}$ phases, there were some controversies about the assignments of the individual components of $\mathrm{C} 1 s$ and $\mathrm{N} 1 s$ core level spectra in the literature $[22,45]$.

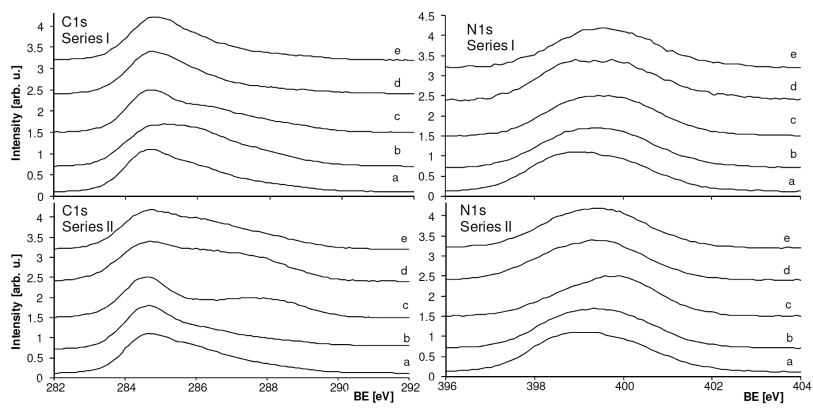

Fig. 4. XPS C $1 s$ and N $1 s$ core level spectra of a-CN $\mathrm{CN}_{x}$ series I and II films for different nitrogen pressures $(a=$ $10 \mathrm{~Pa}, b=100 \mathrm{~Pa}, c=300 \mathrm{~Pa}, d=500 \mathrm{~Pa}$ and $e=$ $1000 \mathrm{~Pa})$

Figure 4 shows the XPS C $1 s$ and N $1 s$ core level spectra of carbon nitride films (series I and II) prepared at various nitrogen pressures. In the two cases (series I and II) the $\mathrm{C} 1 s$ spectra show asymmetric broad peaks, which indicate to the presence of different types of bonds in the deposited films [22, 45-47].

Moreover, the $\mathrm{C} 1 s$ binding energy remains almost constant at $284.5 \mathrm{eV}$ for the entire range of nitrogen pressure in series I and II. However, one may reveal a clear gradual increase of asymmetry and broadening of the $\mathrm{C} 1 \mathrm{~s}$ line shape with a distinct tailing toward higher binding energy showing that the environment of carbon is becoming more heterogeneous with the increase of nitrogen pressure. On the other hand, a shift toward higher binding energy in the $\mathrm{N} 1 s$ peak is observed for the series II film prepared at nitrogen pressure of $300 \mathrm{~Pa}$; this could refer to the formation of more nitrogen atoms bonded to carbon in $s p^{2}$ trigonal configuration.

Figure 5 shows the ratio of nitrogen content to carbon $([\mathrm{N}] /[\mathrm{C}]$ ) of carbon nitride films (series I and II) prepared at various nitrogen pressures evaluated by the area of $\mathrm{C}$ $(1 s)$ and $\mathrm{N}(1 s)$ spectra. Obviously, one can notice that, apart from the point corresponding to $P_{\mathrm{N} 2}=100 \mathrm{~Pa}$, all the values of $[\mathrm{N}] /[\mathrm{C}]$ of carbon nitride films (series II) are higher than those in series I. Let us note that the ratios of carbon, nitrogen and oxygen contents of carbon nitride films (series II) behave in an opposite manner to those of series I with increasing $P_{\mathrm{N} 2}$ as shown in Fig. 6 . From these results, the increase of nitrogen content in the films using microwave NPA could be ensured. Table summarizes elemental composition $\mathrm{C}, \mathrm{N}, \mathrm{O}$ contents, the

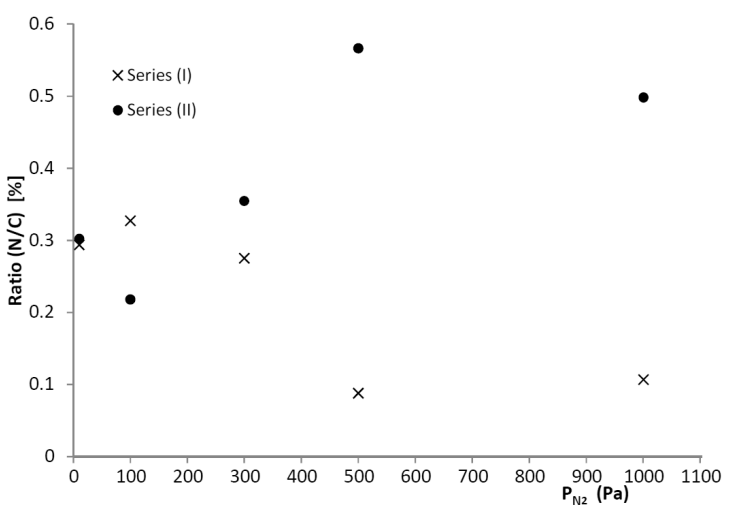

Fig. 5. Ratio of nitrogen content to carbon one $([\mathrm{N}] /[\mathrm{C}])$ of a- $\mathrm{CN}_{x}$ series I and II films for different nitrogen pressures $(a=10 \mathrm{~Pa}, b=100 \mathrm{~Pa}, c=300 \mathrm{~Pa}$, $d=500 \mathrm{~Pa}$ and $e=1000 \mathrm{~Pa})$.

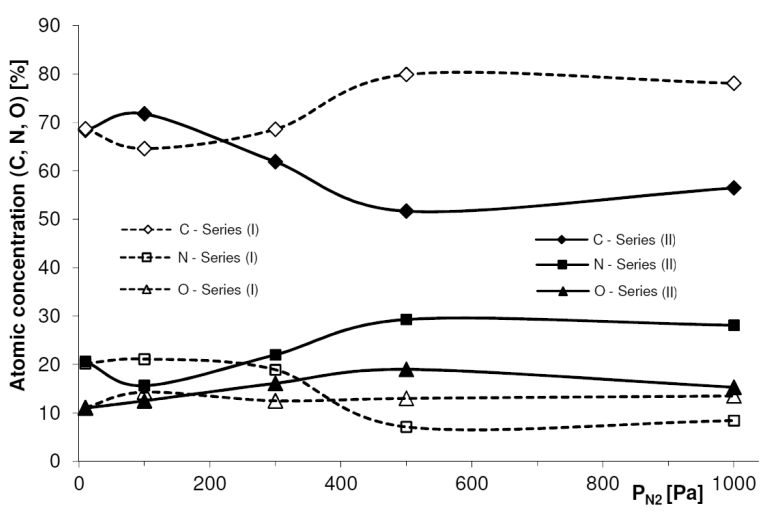

Fig. 6. Variation of the atomic concentration of carbon, nitrogen and oxygen as a function of nitrogen pressure for both series I and II.

ratios of nitrogen content to carbon one $([\mathrm{N}] /[\mathrm{C}])$ and the ratios of oxygen content to carbon one $([\mathrm{O}] /[\mathrm{C}])$ for a- $\mathrm{CN}_{x}$ films in series I and II.

In this work, for the purpose of investigating the bonding configurations of carbon and nitrogen atoms in our a- $\mathrm{CN}_{x}$ films, both $\mathrm{C} 1 s$ and $\mathrm{N} 1 s$ spectra were deconvoluted into six and three Gaussian-Lorentzian line shapes respectively, as illustrated in detail on previous XPS study [22].

In fact, previous Fourier transform infrared spectroscopy (FTIR) studies have shown that the fraction of $\mathrm{C} \equiv \mathrm{N}$ bonding is small in our a-CN films and could be neglected; therefore, we do not consider this arrangement any further.

Concerning the $\mathrm{N} 1 s$ spectra they are fitted to three contributions as follows: peak I (398.4-399 eV) related to $\mathrm{N}-\mathrm{C}\left(s p^{3}\right)$, peak II $(399.6-400.2 \mathrm{eV})$ related to $\mathrm{N}-\mathrm{C}$ $\left(s p^{2}\right)$ and peak III at $>401 \mathrm{eV}$ characteristic of $\mathrm{N}-\mathrm{O}$; the main components are peak I and II.

In order to investigate the evolution of nitrogen local environments, the ratio: $\mathrm{M}=\mathrm{N}-\mathrm{C}\left(s p^{3}\right) / \mathrm{N}-\mathrm{C}\left(s p^{3}\right)+$ 


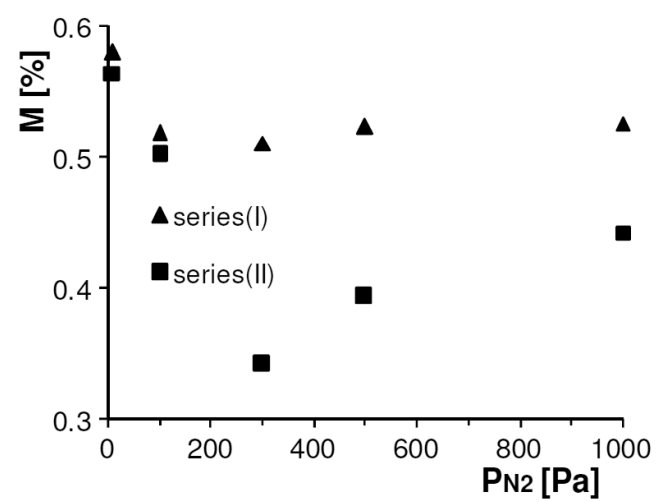

Fig. 7. Influence of NPA on the $\mathrm{M}=\mathrm{N}-\mathrm{C}\left(s p^{3}\right)$ $\mathrm{N}-\mathrm{C}\left(s p^{3}\right)+\mathrm{N}-\mathrm{C}\left(s p^{2}\right)$ ratio in a- $\mathrm{CN}_{x}$ for different nitrogen pressures.

$\mathrm{N}-\mathrm{C}\left(s p^{2}\right)$ calculated from the peak I and II areas, is considered as a good measure indicator. Figure 7 illustrates the influence of the NPA on the nitrogen local environments at different pressures, where all the values of $M$ of carbon nitride films (series II) are lower than that in series I. This implies that the application of NPA is beneficial to the forming of the $\mathrm{N}-\mathrm{C}\left(s p^{2}\right)$ bond in our carbon nitride films.

It is clear that the NPA plays an important role during the deposition of carbon nitride films by supplying reactive nitrogen atoms and ions to the growing film surface, which will lead to an increase of nitrogen content in the films, and also to some transformations of $\mathrm{N}-\mathrm{C}\left(s p^{3}\right)$ to $\mathrm{N}-\mathrm{C}\left(s p^{2}\right)$.

A further spatio-temporal study by time and space resolved optical emission spectroscopy to identify the excited species present in NPA and laser ablation plume for understanding the gas phase processes during the films deposition, is under investigation. This study will involve three experimental conditions: (1) laser ablation of graphite in $\mathrm{N}_{2}$ gas, (2) laser ablation of graphite in NPA and (3) microwave NPA only (gas phase giving an important information about some elements in the NPA which could react with the carbon ablation plume nearby the substrate and/or engage with some surface reaction during the deposition of carbon nitride films). These results suggest that introduction of the NPA may promote chemical reaction of carbon nitride molecule formation either in gas phase or on the surface of the carbon nitride film during its deposition. More work is under way to disclose further details.

\subsection{Surface morphology}

The surface morphology and texture of carbon nitride films was analyzed by SEM and AFM microscopes. The SEM images of all carbon nitride films prepared by laser ablation in $\mathrm{N}_{2}$ gas (series I) or NPA (series II) show an inhomogeneous granular surface formed from particles of several nanometers to tens of nm in diameter and coalesced together into clusters forming cauliflower-like grains.

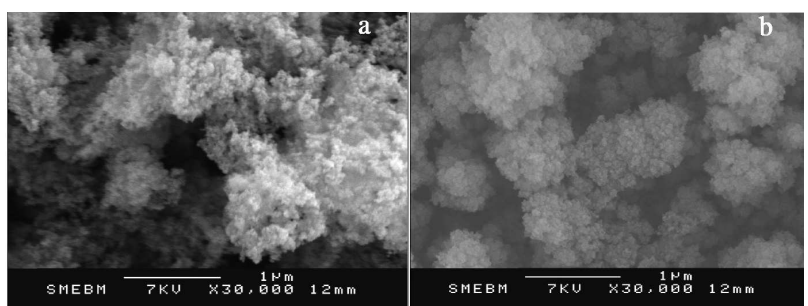

Fig. 8. Comparison between two SEM images at $30000 \times$ magnification of a- $\mathrm{CN}_{x}$ prepared under nitrogen pressure of $500 \mathrm{~Pa}$ (a) (series I) and (b) (series II).

Figure 8 shows a comparison between two SEM images at $30000 \times$ magnification of carbon nitride films prepared under (a) (series I) and (b) (series II) at pressure of $500 \mathrm{~Pa}$. It is visible that the cauliflower-like grains in the film prepared under $\mathrm{N}_{2}$ gas (series I) are larger and more inhomogeneous. To investigate the micro and nanostructure of the films, high resolution AFM images were taken.

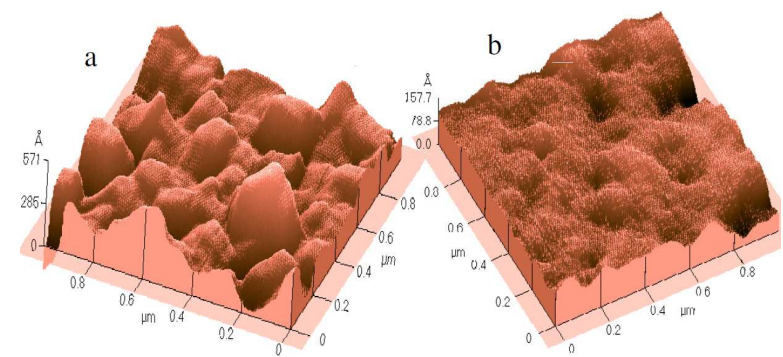

Fig. 9. AFM images of the $1 \times 1 \mu \mathrm{m}^{2}$ of a-CN $\mathrm{CN}_{x}$ prepared under nitrogen pressure of $300 \mathrm{~Pa}$ (a) (series I) and (b) (series II).

Figure 9 shows typical scans of the $1 \times 1 \mu \mathrm{m}^{2}$ of carbon nitride films prepared under (a) (series I) and (b) (series II) at pressure of $300 \mathrm{~Pa}$. Evidently, one can observe that the sizes of the clusters in the film prepared under $\mathrm{N}_{2}$ gas (series I) are up to six orders of magnitude higher than those of series II. To describe the surface topography quantitatively, 2D AFM images of $1 \times 1 \mu \mathrm{m}^{2}$ size and line profile measurements were taken and analyzed with the microscope's own software. The lateral distribution of surface roughness of the series I and II films, as well as the comparison of the two geometries are based on two quantities: the average height $(\mathrm{AH})$, and its root mean square average (RMS) roughness. These measurements give evidence to a decrease in size of clusters and the RMS up to 6 to 10 times for the films prepared under NPA (series II) than those of series I.

Moreover, the typical average height of these clusters on the series I films is higher, i.e. several hundreds of $\mathrm{nm}$, while those on the series II films are in the range $20-50 \mathrm{~nm}$ in height. 
These results are consistent with the Raman results, which show that the decrease of the ratio $I_{D} / I_{G}$ by using a NPA indicates the decrease of size of the graphitic region. This change in the surface topography of the series II films could be due to the migration and rearrangement of particles on the substrate, which imply the annihilation of excess vacancies and/or the elimination of grain boundaries owing to the application of NPA during the deposition of carbon nitride thin films.

\section{Conclusion}

We have deposited amorphous carbon nitride films by microwave remote nitrogen plasma afterglow assisted pulsed laser deposition. It was found that, compared to the PLD in $\mathrm{N}_{2}$ gas, the nitrogen content in the film was enhanced by introduction of nitrogen plasma. This enhancement could be suggested by the increase of $\mathrm{CN}$ content formation in the plume and/or on the surface of the film during its deposition. The chemical bond between carbon and nitrogen was confirmed by the XPS and Raman spectra. The Raman spectroscopy analysis indicated that the application of NPA during carbon nitride films deposition promoted either some degree of limited clustering of the $s p^{2}$ sites or the increase of the $s p^{3}$ bonding fraction. A decrease in size of clusters and cauliflower-like grains for the films prepared under NPA was evidenced from SEM and AFM. This change in the surface topography could be due to the annihilation of excess vacancies and/or the elimination of grain boundaries owing to the application of NPA during the deposition of carbon nitride thin films. In order to determine more physicochemical and structural properties, further studies on a-CN $\mathrm{CN}_{x}$ films particularly the gas phase and other optical characteristics are under investigation.

\section{Acknowledgments}

The authors would like to thank Professor I. Othman, Director General of AEC of Syria for encouragement and support, and thank Dr. S. Al-Khawwaja for assistance. The Institut des Matériaux Jean Rouxel-IMN-Université de Nantes, France is gratefully acknowledged for their cooperation and facilities.

\section{References}

[1] A.Y. Liu, M.L. Cohen, Science 245, 841 (1989).

[2] A.Y. Liu, M.L. Cohen, Phys. Rev. B 41, 10727 (1990).

[3] Th. Malkow, Mater. Sci. Eng. A 292, 112 (2000).

[4] A. Badzian, T. Badzian, R. Roy, W. Drawl, Thin Solid Films 354, 148 (1999).

[5] K.M. Yu, M.L. Cohen, E.E. Haller, W.L. Hansen, A.Y. Liu, I.C. Wu, Phys. Rev. B 49, 5034 (1994).

[6] H. Sjostrom, I. Ivanov, M. Johansson, L. Hultman, J.E. Sundgrwn, Thin Solid Films 246, 103 (1994).

[7] J. Feng, J. Xie, Mater. Lett. 27, 219 (1996).
[8] H. Sjostrom, S. Stafstrom, M. Boman, J.-E. Sundgren, Phys. Rev. Lett. 75, 1336 (1995).

[9] S. Muhl, J.M. Méndez, Diamond Relat. Mater. 8 , 1809 (1999).

[10] T.W. Scharf, R.D. Ott, D. Yang, J.A. Barnard, J. Appl. Phys. 85, 3142 (1999).

[11] A. Wiens, G. Presch-Schuy, R. Hartmann, P. Joeris, J. Vac. Sci. Technol. 18, 2023 (2000).

[12] G. Radnóczi, I. Kovács, O. Geszti, L.P. Bíró, G. Sáfrán, Surf. Coat. Technol. 151-152, 133 (2002).

[13] C. Popovu, L.M. Zambov, M.F. Plass, W. Kulisch, Thin Solid Films 377-378, 156 (2000).

[14] E. Broitman, W. Macdonald, N. Hellgren, G. Radnoczi, Zs. Czigany, A. Wennerberg, M. Jacobsson, L. Hultman, Diamond Relat. Mater. 9-12, 1984 (2000).

[15] F.Z. Cui, D.J. Li, Surf. Coat. Technol. 131, 481 (2000).

[16] M. Marton, E. Zdravecka, M. Vojs, T. Izak, M. Vesely, R. Redhammera, M. Varga, A. Satka, Vacuum 84, 65 (2010).

[17] F. Wen, N. Huang, H. Sun, J. Wang, Y.X. Leng, Surf. Coat. Technol. 186, 118 (2004)

[18] P. Bernhard, Ch. Ziethen, R. Ohr, H. Hilgers, G. Schonhense, Surf. Coat. Technol. 180-181, 621 (2004).

[19] A.K.M.S. Chowdhury, D.C. Cameron, M.S.J. Hashmi, Thin Solid Films 332, 62 (1998).

[20] M. Lejeune, O. Durand-Drouhin, S. Charvet, A. Grosman, C. Ortega, M. Benlahsen, Thin Solid Films 444, 1 (2003).

[21] C. Jama, O. Dessaux, P. Goudmand, J.-M. Soro, D. Rats, J. von Stebut, Surf. Coat. Technol. 59, 116 (1999).

[22] C. Jama, A. Alkhawwam, A.-S. Loir, P. Goudmand, O. Dessaux, L. Gengembre, J. Grimblot, Surf. Interface Anal. 31, 815 (2001).

[23] F.L. Freire Jr., G. Mariotto, C.A. Achete, D.F. Franceschini, Surf. Coat. Technol. 74-75, 382 (1995).

[24] D. Sarangi, R. Sanjines, A. Karimi, Carbon 42, 1107 (2004).

[25] J. Takadoum, J.Y. Rauch, J.M. Cattenot, N. Martin, Surf. Coat. Technol. 174-175, 427 (2003).

[26] B. Angleraud, P.Y. Tessier, Surf. Coat. Technol. 180-181, 59 (2004).

[27] A. Lagrini, S. Charvet, M. Benlahsen, C. Debiemme-Chouvy, C. Deslouis, H. Cachet, Thin Solid Films 482, 41 (2005).

[28] J.R. Shi, Y.J. Xu, J. Zhang, Thin Solid Films 483 , 169 (2005).

[29] A. Alkhawwam, C. Jama, O. Dessaux, P. Goudmand, Thin Solid Films 408, 15 (2002).

[30] X.K. Shen, J. Sun, N. Xu, Z.F. Ying, L.Q. Shi, A.M. Wu, Z.S. Gong, J.D. Wu, Diamond Relat. Mater. 16, 418 (2007).

[31] C. Jama, V. Rousseau, O. Dessaux, P. Goudmand, Thin Solid Films 302, 58 (1997).

[32] C. Niu, Y.Z. Lu, C.M. Lieber, Science 261, 334 (1993). 
[33] A.P. Caricato, G. Leggieri, A. Luches, A. Perrone, E. Gyorgy, I.N. Mihailescu, M. Popescu, G. Barucca, P. Mengucci, J. Zemek, M. Trchova, Thin Solid Films 307, 54 (1997).

[34] Y.H. Cheng, Z.H. Sun, B.K. Tay, S.P. Lau, X.L. Qiao, J.G. Chen, Y.P. Wu, C.S. Xie, Y.Q. Wang, D.S. Xu, S.B. Mo, Y.B. Sun, Appl. Surf. Sci. 182, 32 (2001).

[35] J. Zemek, M. Jelinek, V. Vorlicek, M. Trchova, J. Lancok, Diamond Relat. Mater. 9, 548 (2000).

[36] Z.Y. Chen, J.P. Zhao, T. Yano, T. Ooie, Diamond Relat. Mater. 11, 1629 (2002).

[37] Z.B. Dong, Y.F. Lu, K. Gao, L.Q. Shi, J. Sun, N. Xu, J.D. Wu, Thin Solid Films 516, 8594 (2008).

[38] S.E. Rodil, S. Muhl, S. Maca, A.C. Ferrari, Thin Solid Films 433, 119 (2003).

[39] A.C. Ferrari, S.E. Rodil, J. Robertson, Phys. Rev. B 67, 155306 (2003).

[40] C. Casiraghi, A.C. Ferrari, J. Robertson, Phys. Rev. B 2, 085401 (2005)
[41] A.C. Ferrari, J. Robertson, Phys. Rev. B 61, 14095 (2000).

[42] Y.H. Cheng, B.K. Tay, S.P. Lau, X. Shi, X.L. Qiao, Z.H. Sun, J.G. Chen, Y.P. Wu, C.S. Xie, Diamond Relat. Mater. 10, 2137 (2001).

[43] Y. Taki, T. Kitagawa, O. Takai, Thin Solid Films 304, 183 (1997).

[44] F. Alibart, O. Durand Drouhin, M. Benlahsen, S. Muhl, S. Elizabeth Rodil, E. Camps, L. Escobar-Alarcon, Appl. Surf. Sci. 254, 5564 (2008).

[45] W.J. Gammon, O. Kraft, A.C. Reilly, B.C. Holloway, Carbon 41, 1917 (2003).

[46] I. Bertoti, T. Szorenyib, F. Antoni, E. Fogarassy, Diamond Relat. Mater. 11, 1157 (2002).

[47] M.A. Baker, P. Hammer, Surf. Interface Anal. 25 , 629 (1997). 